\title{
AVALIAÇÃO DA SUSTENTABILIDADE DE UM EMPREENDIMENTO DE HIS DO PMCMV, ATRAVÉS DO SELO CASA AZUL
}

\section{A SUSTAINABILITY ASSESSMENT OF A SOCIAL HOUSING INITIATIVE (HIS) BELONGING TO THE PMCMV (MY HOUSE, MY LIFE HOUSING PROGRAM), USING THE "SELO CASA AZUL" (BLUE HOUSE SEAL) ASA TOOL}

\section{Denise de C. Provenzano, M.Sc (UFRJ); Leopoldo E. G. Bastos, Dr. (UFRJ)}

\author{
Palavras Chave \\ Sustentabilidade; HIS; PMCMV; Selo Casa Azul
}

\section{Key Words}

Sustainability; HIS (Social Housing Initiative); PMCMV (My House, My Home Housing Project); Selo Casa Azul (Blue House Seal)

\section{RESUMO}

Este estudo buscou avaliar a questão da sustentabilidade num empreendimento de habitação de interesse social (HIS) do Programa Minha Casa Minha Vida (PMCMV) através do Selo Casa Azul. Foi escolhido o Projeto Residencial Bairro Carioca, na cidade do Rio de Janeiro, com excelente inserção na malha urbana, aproveitamento de edificações antigas e descontaminação do solo. Através da checagem dos critérios que compõem esta certificação, constatou-se que este empreendimento não seria certificado por não atender a alguns critérios obrigatórios. $O$ baixo valor da unidade habitacional imposto para a faixa 1 do PMCMV, é um dos fatores que mais dificulta o cumprimento de alguns critérios. Também a busca pela maior quantidade possível de unidades habitacionais não permite uma implantação destes blocos segundo melhor orientação solar e ventilação predominante. A obrigatoriedade da certificação mínima, nível bronze, para esses empreendimentos de HIS resultaria numa habitação de melhor qualidade para essa população mais carente.

\section{ABSTRACT}

This study aimed to evaluate the sustainability issues in a HIS (Social Housing initiative) project belonging to the PMCMV (My House My Life housing program) using the rating system "Selo Casa Azul" (Blue House Seal). The selected Project was the "Residencial Bairro Carioca", located in Rio de Janeiro, which is well inserted into the urban fabric, used old buildings (retrofit) and decontaminated the soil. After reviewing the certification criteria it was shown that the Project would fail to receive it as it did not meet some of the mandatory criteria. The most important reason why such criteria could not be met is the low price of the houses imposed by the PMCMV to the level 1. As there was the need to build the greatest number possible of housing units it was very hard to position these blocks oriented towards a better sunlight and ventilation conditions. Compulsory minimum certification (bronze level) for the HIS enterprises would result in better quality housing for the neediest people. 


\section{INTRODUÇÃO}

É fato notório que a indústria da construção civil é o setor de atividades humanas que mais consome recursos naturais e utiliza energia de forma intensiva, gerando consideráveis impactos ambientais e uma grande quantidade de resíduos sólidos, líquidos e gasosos. Isso explica a urgente necessidade deste setor produtivo se adequar às agendas de sustentabilidade.

A publicaçãona página do Instituto para o Desenvolvimento da Habitação Ecológica - IDHEA (2016) define Construção Sustentável como aquela que "promove alterações conscientes no entorno, de forma a atender as necessidades de edificação e uso do homem moderno, preservando o meio ambiente e os recursos naturais, garantindo qualidade de vida para as gerações atuais e futuras".

Nesta direção, várias iniciativas têm sido tomadas em todo o mundo para o desenvolvimento de métodos para avaliar a sustentabilidade das edificações. Estes métodos são essenciais porque sem a definição de parâmetros e metas não há como verificar o atendimento a essas questões, que variam de acordo com o país em que essas construções estão localizadas.

O Brasil não possui uma certificação oficial para aferir os critérios de sustentabilidade das edificações; a primeira iniciativa foi o selo PROCEL Edifica, desenvolvido pela Eletrobrás/Procel para avaliar a eficiência energética das edificações. Em seguida, mas buscando abranger de forma mais completa os conceitos de sustentabilidade, veio o Selo Casa Azul da CAIXA, para imóveis residenciais apenas. O selo AQUA, uma adaptação do procedimento francês HQE - Haute Qualité Environnementale, também tem sido bastante utilizado, mas é o americano LEED - Leadership in Energy and Environmental Design que lidera em termos de quantidade de empreendimentos já certificados.

No tocante à habitação de interesse social (HIS), onde as questões de custo-benefício são geralmente extremadas, constitui um desafio conciliar as premissas de sustentabilidade com projetos dessa natureza. Em muitos empreendimentos de HIS tem sido constatada a baixa qualidade das edificações, além de seu grande porte, mal localizados, mal construídos, mas para as famílias pobres resulta como única alternativa à favelização (MAGALHÃES, 2011).

Em março de 2009 foi lançado o Programa Minha Casa Minha Vida (PMCMV) que teve como meta inicial construir em curto prazo um milhão de moradias com recursos do Orçamento Geral da União e do FGTS. Neste programa, o construtor solicita crédito à CAIXA a partir de projetos que tenham sido aprovados pelas Prefeituras. De acordo com o tipo de empreendimento a ser construído, as unidades devem ser comercializadas por um valor dentro de limites estabelecidos segundo as características da cidade e da região, e segundo as faixas de renda familiar a serem atendidas; assim são definidos os subsídios, os mecanismos financeiros e comerciais (CARDOSO, 2013).

De acordo com o Ministério das Cidades (2016), as duas primeiras etapas do programa já entregaram cerca de 2,6 milhões de residências e mais de 1,5 milhão de unidades encontram-se em construção. Apesar de ser o programa que mais privilegiou a classe menos favorecida da população, é notória a necessidade de reavaliação de seus projetos, em busca por uma melhoria da qualidade dos empreendimentos.

Procura-se na presente pesquisa analisar, através do estudo de caso de um empreendimento de HIS do PMCMV, se uma certificação, mesmo que no seu nível mais básico, conseguiria garantir um nível razoável de sustentabilidade para este tipo de empreendimento habitacional. Foi escolhido então o Selo Casa Azul, uma vez que a CAIXA é a instituição financeira responsável por liberar crédito para empreendimentos do PMCMV, além de ser uma certificação nacional específica para habitação e de baixíssimo custo de adesão.

\section{O BAIRRO CARIOCA}

Como objeto de estudo deste trabalho, buscou-se um empreendimento de HIS do PMCMV certificado com o Selo Casa Azul situado na cidade do Rio de Janeiro. Porém, como até o momento nenhum empreendimento deste tipo alcançou esta certificação nesta cidade, foi selecionado o Projeto Residencial Bairro Carioca em Triagem, na Zona Norte do município, que já possui algumas características positivas para serem analisadas sob a ótica da sustentabilidade.

- Retrofit de algumas construções antigas existentes no terreno, do antigo Centro de Distribuição e Logística da Light, concessionária dos serviços de energia elétrica da cidade, que ali se manteve por 80 anos.

- Descontaminação prévia do solo devido a presença de resíduos industriais decorrentes de seu prolongado uso pela Light.

- Boa localização do empreendimento, junto a linha 2 do metrô, que cumpre o trajeto ao Centro em 15 minutos, além da existência de várias linhas de ônibus e pela proximidade da estação ferroviária.

- Preservação de árvores adultas existentes no terreno. 
Figura 01 - Vista do Bairro Carioca

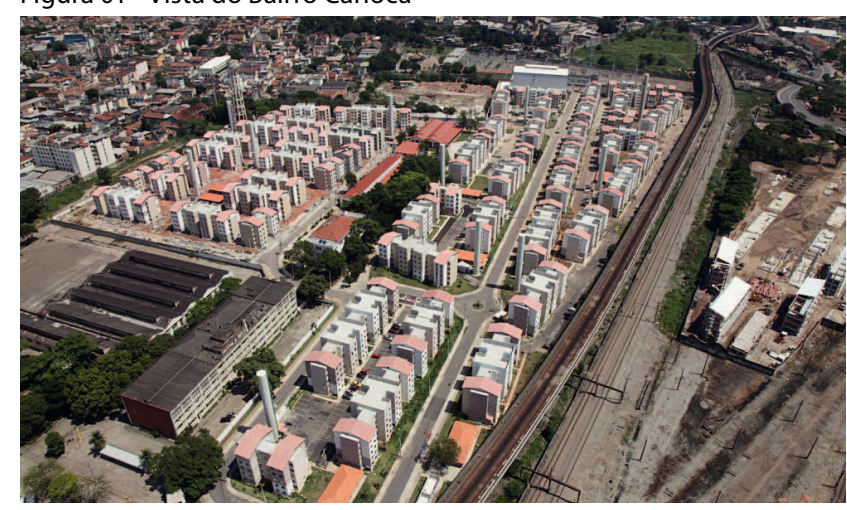

Fonte: McTARNAGHAN,2014

\subsection{Contextualização do Empreendimento com seu entorno}

O empreendimento se situa na cidade do Rio de Janeiro - RJ, na região Sudeste do Brasil, ao nível do mar, tendo como coordenadas geográficas: Latitude: $22^{\circ} 54^{\prime}$ 10" S e Longitude: 430 12' 27" W (GEOGRAFOS, 2016).

O clima do Rio de Janeiro é classificado como tropical atlântico, com baixas amplitudes térmicas. A temperatura média anual é de $23,8^{\circ} \mathrm{C}$, possuindo verões quentes e úmidos e invernos amenos e com regime de chuvas mais restrito. A média pluviométrica é de $1.069,4 \mathrm{~mm}$ anuais,

\subsection{Descrição do Empreendimento}

O Projeto Residencial Bairro Carioca foi estruturado a partir de uma parceria público-privada entre os governos Municipal e Federal, o Programa MCMV, a Caixa Econômica Federal e a concessionária de energia elétrica Light, antiga proprietária do terreno (PREFEITURA DA CIDADE DO RIO DE JANEIRO, 2011).

O projeto arquitetônico, de autoria da STA Arquitetura, incluiu o retrofit de algumas edificações históricas do antigo Centro de Distribuição e Logística da Light, buscando aliar uma adequada qualificação urbana com o maior número de unidades residenciais possível, dentro das normas de financiamento do PMCMV. Houve também necessidade de atender aos parâmetros edilícios deste programa, como áreas mínimas das unidades e sistemas construtivos. A descontaminação prévia do terreno foi necessária devido à presença de resíduos no solo remanescentes de seu prolongado uso industrial.

A área total do terreno do Bairro Carioca é de 122.567 $\mathrm{m} 2$, composto por 60 edifícios de 5 andares (térreo +4 pavimentos), agrupados em 11 condomínios (lotes), ilustrados na planta de situação na Figura 2. No total são 2.240 apartamentos de sala, dois quartos, cozinha, banheiro e área de serviço, cada um com área construída de 43,89 $\mathrm{m} 2$, sendo $39,61 \mathrm{~m} 2$ de área útil.

A população estimada na fase de projeto foi de 8.960 moradores. Dentre os equipamentos e serviços básicos integrantes do empreendimento temos: clínica da família, creche, escola primária, centro cívico cultural, posto policial, mercado, centro esportivo, praças, ciclovia, parquinhos, churrasqueiras e áreas verdes.

Figura 02 - Planta de situação

\section{O PROJETO}

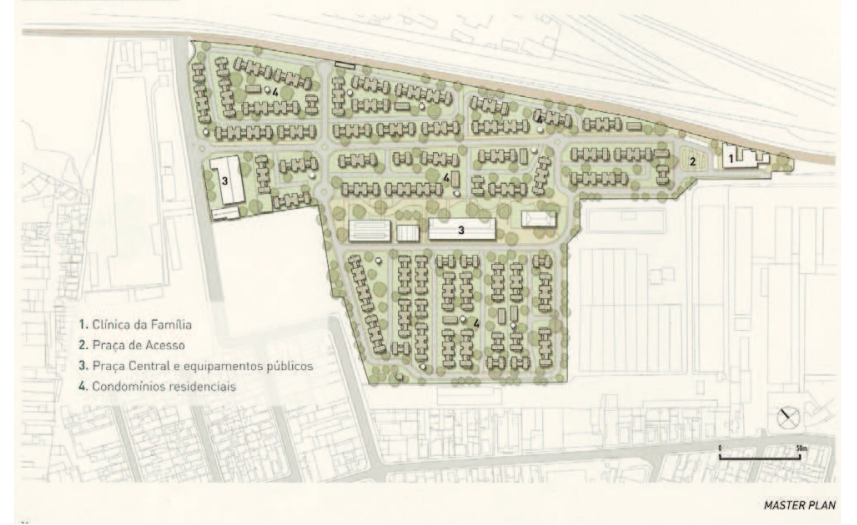

Fonte: Prefeitura da Cidade do Rio de Janeiro 2011. melhoradas pela renovação do ar em seu interior, devido à boa ventilação dos ambientes. 


\section{O SELO CASA AZUL}

"O Selo Casa Azul, lançado em 2010, é de adesão voluntária e teve o intuito de incentivar o uso racional de recursos naturais na construção de empreendimentos habitacionais, de reduzir o custo de manutenção dos edifícios e as despesas mensais de seus usuários, além de promover a conscientização de empreendedores e moradores das vantagens da construção sustentável. Sua concessão é feita durante a análise de viabilidade técnica do empreendimento tendo como pré-requisitos atendimento às regras dos programas operacionalizados pela CAIXA de acordo com a linha de financiamento ou produto de repasse (CAIXA, 2010)."

A certificação contempla seis categorias, cada uma com seus critérios, alguns deles obrigatórios e outros de livre escolha, perfazendo um total de 53 critérios; são três os tipos de classificação do selo passíveis de serem concedidos, conforme Figura 3.

Figura 03 - Critérios por Categoria do Selo e sua gradação

\section{Obtenção Selo Casa Azul}

\section{NIVEIS DE GRADAÇÃO SELO AZUL:}

\begin{tabular}{|c|c|}
\hline Gradaçăo & Atendimento minimo \\
\hline BRONZE & Criténios obrigatónios \\
\hline PRATA & $\begin{array}{l}\text { Criténios obrigatónios e mais } \\
6 \text { criterios de livre escolha }\end{array}$ \\
\hline OURO & $\begin{array}{l}\text { Criténios obrigatónios e mais } \\
12 \text { criternos de livre escolha }\end{array}$ \\
\hline
\end{tabular}

CRITERIOS/CATEGORIAS DE CLASSIFICAÇĀO:

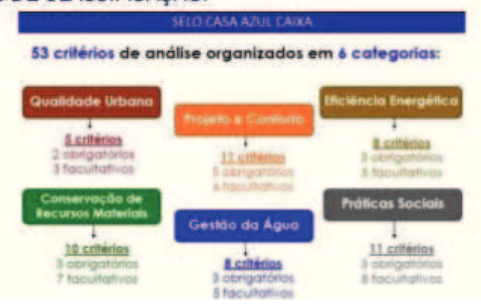

Fonte: CAIXA Selo Casa Azul, 2016.

Conforme Manual do Selo Casa Azul, o atendimento aos itens propostos em projeto será verificado também no curso do acompanhamento da obra, durante as medições mensais ou em vistorias específicas. Não há despesa significativa para a concessão do Selo, apenas é cobrada uma taxa de análise de projeto ao candidato ao Selo Casa Azul CAIXA, para cobertura dos custos da análise técnica. Seu valor é definido pela fórmula: Taxa $=40,00+7(n-1)$, onde $n=n^{\circ}$ de unidades, limitada a um teto de $R \$ 328,00$.

\section{APLICAÇÃO DO SELO CASA AZUL NO ESTUDO DE CASO}

Com base nas informações e documentação fornecidas pelo arquiteto Celso Rayol, na época atuando na STA Arquitetura como responsável pelo desenvolvimento do projeto, além de visita ao empreendimento e informações obtidas com profissionais da Secretaria Municipal da Habitação da Prefeitura do Rio de Janeiro, foi possível efetuar a análise dos critérios para certificação do Selo Casa Azul aplicada ao Residencial Bairro Carioca.

Foi utilizado o Manual Selo Casa Azul - Boas Práticas para Habitação Mais Sustentável (2010), já com as alterações introduzidas a partir de Março de 2014. Tais alterações tiveram como principal objetivo atualizar e adequar a metodologia às normas e diretrizes voltadas à elaboração de projetos habitacionais, como a NBR 15575/2013, e ao PROCEL Edifica para residências. Os critérios obrigatórios de cada categoria da certificação estão identificados com um asterisco $\left(^{*}\right)$.

\section{CATEGORIA 1: Qualidade Urbana}

Esta categoria busca avaliar a localização do empreendimento e sua inserção na malha urbana, de modo que seja possível avaliar os impactos positivos da vizinhança ao bem-estar de seus moradores. Outros aspectos considerados são as ações para requalificação urbana, o mapeamento de infraestrutura básica, serviços, equipamentos e transporte público regular devem ser realizados na etapa de estudo de viabilidade.

O subitem 1.1 ( ${ }^{*}$ Qualidade do entorno - infraestrutura) busca verificar se a inserção do empreendimento na malha urbana é no mínimo dotada de: rede de abastecimento de água potável, pavimentação, energia elétrica, iluminação pública, esgotamento sanitário, drenagem, transporte público, dois pontos de comércio e serviços básicos, escola pública de ensino fundamental, equipamento de saúde e lazer (caso não haja no empreendimento). Atende (O Bairro Carioca possui vários dos equipamentos exigidos em seu interior).

O subitem 1.2 ( ${ }^{*}$ Qualidade do entorno - impactos) tem como objetivo o bem-estar, a segurança e a saúde dos moradores, considerando o impacto do entorno em relação ao empreendimento. Não são admitidos em seu entorno (raio $\geq 2,5 \mathrm{~km}$ ) fatores considerados prejudiciais ao bem-estar, à saúde ou à segurança dos moradores, tais como: fontes de ruídos excessivos e constantes (rodovias, aeroportos, indústrias) além de odores e poluição excessivos e constantes, advindos de estações de tratamento de esgoto, lixões e etc. Não Atende (ruído constante para 
os prédios localizados junto à divisa nordeste do terreno, colada a linha férrea Ramal Belford Roxo e a linha 2 do metrô).

Figura 04: Viaduto junto ao muro do Bairro Carioca

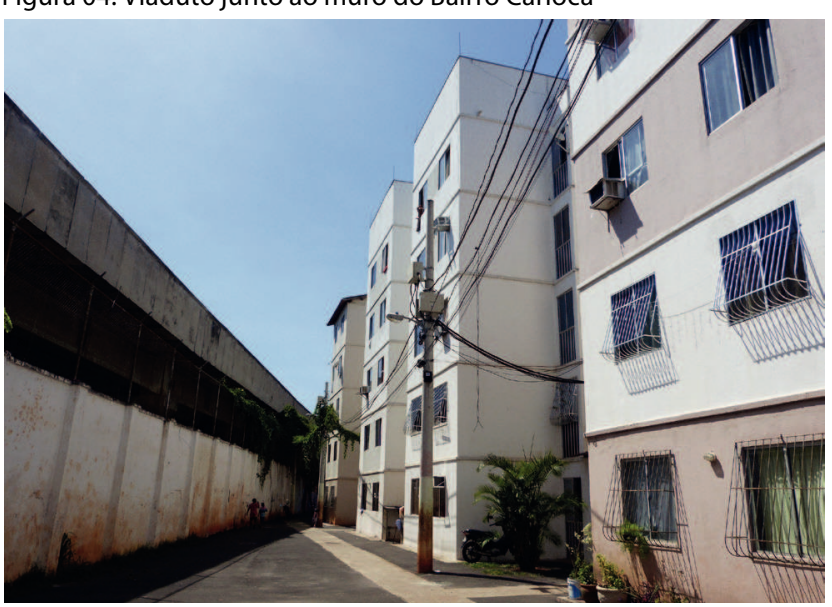

Fonte: Autores

O subitem 1.3 (Melhorias no entorno) tem como objetivo incentivar ações para melhorias estéticas, funcionais, paisagísticas e de acessibilidade no entorno do empreendimento. Atende (foi priorizado o conceito de integração do sistema viário do empreendimento à malha urbana circundante, a preservação do bosque existente no terreno, além do retrofit de diversos galpões e construções antigas).

O subitem 1.4 (Recuperação de Áreas Degradadas) permite pontuar proposta que vise à recuperação de área degradada igual ou superior a $20 \%$ da área total do empreendimento. Atende (Foi feita uma descontaminação prévia do solo devido à presença de resíduos industriais no solo).

O subitem 1.5 (Reabilitação de Imóveis) busca incentivar a reabilitação de edificação ou construção em vazios urbanos. Atende (foram reabilitadas 5 edificações antigas existentes para abrigar equipamentos públicos na praça central do Bairro (arioca).

\section{CATEGORIA 2: Projeto e Conforto}

Esta categoria trata dos aspectos relacionados ao planejamento e à concepção do projeto do empreendimento, principalmente à adaptação da edificação às condições climáticas, às características físicas e geográficas locais, e previsão de espaços com fins específicos.

O subitem 2.1 (*Paisagismo) busca através de elementos paisagísticos interferir nas edificações visando melhorar o desempenho térmico. Não atendido (foram mantidas na praça principal muitas árvores de médio e grande porte; mas junto aos prédios habitacionais são raras).

O subitem 2.2 (Flexibilidade de Projeto) tem como objetivo permitir o aumento da versatilidade da edificação, por meio de modificação de projeto e futuras ampliações, adaptando-se às necessidades do usuário. Não atendido (paredes de concreto estruturais).

O subitem 2.3 (Relação com a vizinhança) busca minimizar os impactos negativos do empreendimento sobre a vizinhança, através de medidas que propiciem à vizinhança condições adequadas de insolação, luminosidade, ventilação e vista. Não atendido.

O subitem 2.4 (Solução alternativa de Transporte) incentiva o uso de meios de transporte menos poluentes, através de bicicletários, ciclovias ou de transporte coletivo privativo do condomínio. Não atendido (existem poucos trechos de ciclovias ao longo das vias internas, mas não há bicicletários).

O subitem 2.5 (* Local para coleta seletiva) determina a existência de local adequado no projeto para coleta, seleção e armazenamento de material reciclável. Não Atendido.

O subitem 2.6 ( ${ }^{*}$ Equipamentos de Lazer, Sociais e Esportivos) tem como objetivo incentivar práticas saudáveis de convivência e entretenimento dos moradores, mediante a implantação de equipamentos de lazer, sociais e esportivos. Atendido (existência de Centro Esportivo, Centro Cívico e vários salões de festas, um para cada lote).

O subitem 2.7 ( ${ }^{*}$ Desempenho Térmico - Vedações) visa proporcionar ao usuário melhores condições de conforto térmico, conforme as diretrizes gerais para projeto correspondentes à zona bioclimática do local do empreendimento, ZB 8. Não atendido (os dois tipos de cobertura dos prédios residenciais não passam nos critérios exigidos).

O subitem 2.8 (*Desempenho Térmico - Orientação ao Sol e Ventos) busca condições de conforto térmico ao usuário mediante estratégias de projeto, conforme a zona bioclimática do local, considerando-se a implantação da edificação em relação à orientação solar, aos ventos dominantes e à interferência de elementos físicos do entorno, construídos ou naturais. Obrigatória apenas para as ZB 1,2 e 3 e recomenda-se a adoção de elementos de sombreamento aos cômodos de longa permanência voltados para a face oeste nas demais ZBs. Não Atendido (apesar de tratar-se apenas de uma recomendação para a ZB8, após as alterações nos critérios do Selo em 2014).

O subitem 2.9 (lluminação Natural de Áreas Comuns) tem como objetivo melhorar a salubridade das áreas comuns e diminuir o consumo de energia; existência de abertura voltada para o exterior da edificação com área mínima de $12,5 \%$ da área de piso do ambiente. Atendido (possui janela nos halls dos andares com 15,5\% da área do piso).

O subitem 2.10 (Ventilação e lluminação Natural de Banheiros) busca melhorar a salubridade do ambiente além de diminuir o consumo de energia; existência de 
abertura voltada para o exterior com área mínima de $12,5 \%$ da área de piso do banheiro. Atendido.

O subitem 2.11 (Adequação as Condições Físicas do Terreno) visa minimizar o impacto causado pela implantação do empreendimento na topografia e em relação aos elementos naturais. Atendido (terreno plano, com preservação de árvores adultas).

\section{CATEGORIA 3: Eficiência Energética}

Esta categoria privilegia o uso de equipamentos mais econômicos, com foco na eficiência energética, além do uso de energia renovável. Ênfase aos sistemas de medição individualizada.

O subitem 3.1 (*Lâmpadas de baixo consumo - áreas privadas) busca reduzir o consumo de energia através de lâmpadas eficientes, principalmente nos empreendimentos de HIS. Não atendido (unidades entregues sem lâmpadas).

O subitem 3.2 ( ${ }^{*}$ Dispositivos economizadores - áreas comuns) busca reduzir o consumo de energia através de lâmpadas eficientes, nas áreas comuns. Atendido.

O subitem 3.3 (Sistema de Aquecimento Solar) busca reduzir o consumo de energia elétrica ou de gás para o aquecimento de água. Não atendido.

O subitem 3.4 (Sistema de Aquecimento à Gás) tem por objetivo reduzir o consumo de gás com o equipamento mais eficiente. Não atendido.

O subitem 3.5 ( ${ }^{*}$ Medição individualizada - Gás) busca permitir que cada morador gerencie seu consumo de gás, levando a uma diminuição do consumo. Atendido.

O subitem 3.6 (Elevadores eficientes) busca reduzir o consumo de energia. Não se aplica.

O subitem 3.7 (Eletrodomésticos eficientes) busca reduzir o consumo de energia com eletrodomésticos.

\section{Não atendido.}

O subitem 3.8 (Fontes alternativas de energia) busca reduzir o consumo de energia por meio da geração e conservação de energias renováveis como painéis fotovoltaicos, gerador eólico, etc. Não atendido.

\section{CATEGORIA 4: Conservação de Recursos Materiais}

Esta categoria busca assegurar a qualidade dos materiais utilizados, evitando desperdício e incentivando a reciclagem.

O subitem 4.1 (Coordenação Modular) busca reduzir as perdas de materiais através de correta modulação, que também aumenta a produtividade e diminui os resíduos de construção e demolição (RCD). Atendido.

O subitem 4.2 ( ${ }^{*}$ Qualidade de Materiais e Componentes) procura evitar produtos de baixa qualidade, selecionando empresas "qualificadas" pelo Ministério das Cidades pelo Programa Brasileiro de Qualidade e Produtividade no Habitat
(PBQP-H). Atendido (consta do Edital de Chamamento Público para construção do empreendimento).

O subitem 4.3 (Componentes industrializados ou Préfabricados) busca reduzir as perdas de materiais, gerando menos resíduos e reduzindo o consumo de recursos naturais. Ao menos dois itens devem ser compostos de componentes industrializados: (a) fachadas; (b) divisórias internas; (c) estrutura de pisos (lajes) e escadas; (d) pilares e vigas. Atendido (todas as paredes em concreto, moldadas em loco utilizando formas metálicas, com todas as instalações embutida; a geração de resíduos e o desperdício foram bem reduzidos).

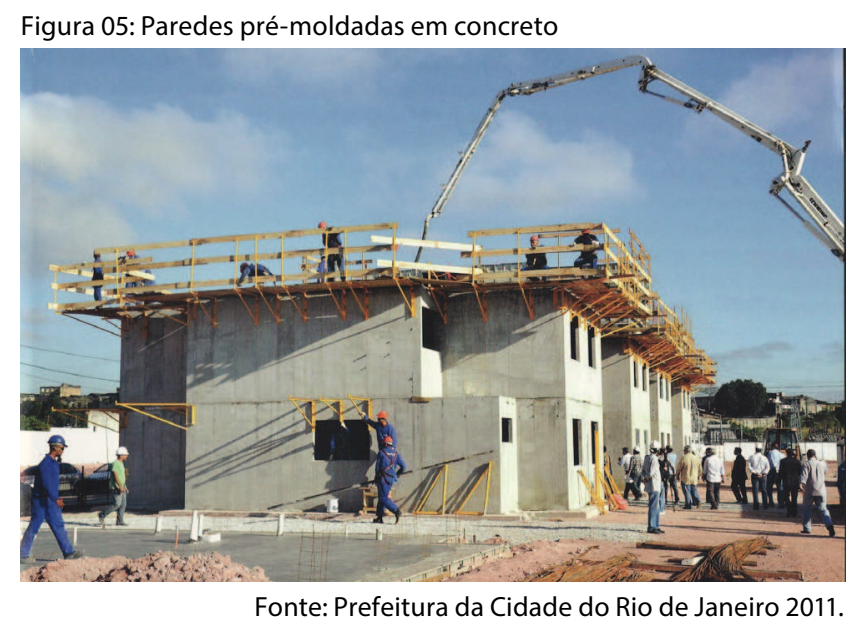

O subitem 4.4 (*Formas e escoras reutilizáveis) tem como objetivo minimizar o emprego de madeira em aplicações de baixa durabilidade, além de promover o uso de materiais reutilizáveis. Atendido (utilizadas formas metálicas, com intenso reuso).

O subitem 4.5 ( ${ }^{*}$ Gestão de Resíduos de Construção e Demolição) busca reduzir a quantidade de resíduos durante a obra, com base nas Resoluções no 307 e 348 do Conama. Existência de um "Projeto de Gerenciamento de Resíduos da Construção Civil - PGRCC" e ao final da obra, comprovar a destinação adequada dos resíduos gerados. Atendido (a construtora Direcional possui a certificação do $P B Q P-H$ que a obriga a ter esse controle).

O subitem 4.6 (Concreto com dosagem otimizada) objetiva otimizar o uso do cimento na produção de concretos estruturais, por meio de processos de dosagem e produção controlados e de baixa variabilidade, sem redução da segurança estrutural, preservando recursos naturais escassos e reduzindo as emissões de $\mathrm{CO} 2$. Atendido.

Osubitem 4.7 (Cimento de Alto-forno (CPIII) e Pozolânico (CP IV)) busca reduzir as emissões de $\mathrm{CO} 2$ associadas à produção do clínquer de cimento Portland utilizando resíduos 
ou materiais abundantes. Atendido (não só pela questão de emissões de $\mathrm{CO} 2$, mas também para que tivesse rápida secagem otimizando a velocidade de produção).

O subitem 4.8 (Pavimentação com RCD) busca reduzir o consumo de recursos naturais não renováveis através de utilização de pavimentação com uso de agregados produzidos pela reciclagem de resíduos de construção e demolição (RCD). Não atendido.

O subitem 4.9 (Madeira Plantada ou Certificada) busca reduzir a demanda por madeiras nativas de florestas não manejadas pela promoção do uso de madeira de espécies exóticas plantadas ou madeira nativa certificada. Atendido (sempre de origem comprovada).

O subitem 4.10 (Facilidade de Manutenção da Fachada) visa reduzir a necessidade de manutenção das fachadas, com pinturas frequentes, especialmente nos empreendimentos de HIS. Não atendido (as fachadas são todas em pintura).

\section{CATEGORIA 5: Gestão da Água}

Esta categoria busca a conservação da água potável, aproveitamento e reuso, além do tratamento dos esgotos. As ações abordadas buscam reduzir o desperdício, tratar os esgotos e garantir a permeabilidade dos solos, facilitando o escoamento das águas pluviais.

O subitem 5.1 (*Medição Individualizada - água). Atendido.

O subitem 5.2 ( ${ }^{*}$ Dispositivos economizadores - Sistema de Descarga). Atendido.

O subitem 5.3 (Dispositivos Economizadores - Arejadores) tem como objetivo reduzir o consumo de água nos lavatórios e nas pias de cozinha. Não atendido.

O subitem 5.4 (Dispositivos Economizadores - Registro regulador de Vazão) busca reduzir o consumo de água nos demais pontos de utilização. Não atendido.

O subitem 5.5 (Aproveitamento de águas pluviais). Não atendido.

O subitem 5.6 (Retenção de Águas Pluviais) visa permitir o escoamento das águas pluviais de modo controlado, evitando inundações através de construção de reservatório de retenção. Não atendido.

O subitem 5.7 (Infiltração de Águas Pluviais) busca favorecer a infiltração das águas pluviais no solo, evitando as inundações, reduzindo a poluição difusa, aliviando a rede pública de drenagem além de recarregar o lençol freático. Atendido.

O subitem 5.8 ( ${ }^{*}$ Áreas Permeáveis) tem como objetivo incentivar o aumento de áreas permeáveis em pelo menos $10 \%$ acima do exigido pela legislação local. Atendido.

\section{CATEGORIA 6: Práticas Sociais}

Essa categoria busca promover a sustentabilidade do empreendimento por meio de ações que abrangem os diversos agentes envolvidos na elaboração do projeto, construção e ocupação das edificações. Visam também a ampliação da consciência ambiental, além de contribuir para a redução de algumas desigualdades sociais.

O subitem 6.1 ( ${ }^{*}$ Educação para a Gestão de RCD) tem por objetivo promover atividades educativas entre os empregados envolvidos na construção, e motivá-los para a execução das diretrizes do Plano de Gestão do RCD. Não Atendido.

O subitem 6.2 (*Educação Ambiental dos Empregados) busca orientar os trabalhadores sobre a utilização dos itens de sustentabilidade do empreendimento, principalmente quanto aos aspectos ambientais. Não Atendido.

O subitem 6.3 (DesenvolvimentoPessoal dosEmpregados) busca melhorar a condição de vida dos trabalhadores através da educação. Não atendido.

O subitem 6.4 (Capacitação Profissional dos Empregados) tem por objetivo prover capacitação profissional aos trabalhadores buscando melhorar seu desempenho e sua condição socioeconômica. Atendido (houve um programa de capacitação de serventes para oficiais como pedreiros, montadores, etc.).

O subitem 6.5 (Inclusão dos trabalhadores locais) propõe a contratação de moradores da área de intervenção e entorno ou de futuros moradores do empreendimento, num um percentual mínimo de $20 \%$ do total de empregados da obra. Não atendido.

O subitem 6.6 (Participação da Comunidade na Elaboração do Projeto) tem como objetivo estimular a permanência dos moradores no imóvel além de sua valorização, através da participação e envolvimento dos mesmos desde a sua concepção. Não atendido.

O subitem 6.7 ( ${ }^{*}$ Orientação aos Moradores) pressupõe a orientação aos moradores quanto ao uso e manutenção adequada do imóvel, além de fornecimento do manual de utilização do mesmo. Atendido (pela Direcional na entrega das unidades).

O subitem 6.8 (Educação Ambiental dos Moradores) objetiva orientar os moradores sobre as questões ambientais e os demais eixos que compõem a sustentabilidade, através de um plano de Educação Ambiental sobre uso racional e redução de consumo dos recursos naturais e energéticos, coleta seletiva, dentre outros. Não atendido.

O subitem 6.9 (Capacitação para gestão do Empreendimento) busca a organização social dos moradores, capacitando-os para a gestão do empreendimento. Não atendido (parcial; somente em alguns lotes houve a formação de um grupo de gestores). 
O subitem 6.10 (Aç̃̃es para Mitigação de Riscos Sociais) propicia a inclusão social de população em situação de vulnerabilidade social, bem como desenvolvendo ações sócio-educativas para os demais moradores da área e entorno visando reduzir o impacto do empreendimento, além de favorecer a resolução de possíveis conflitos gerados pela construção e inserção de novos habitantes na comunidade já instalada. Não atendido.

O subitem 6.11 (Ações para a Geração de Emprego e Renda) busca promover o desenvolvimento socioeconômico dos moradores através de plano de Geração de Trabalho e Renda que contemple atividades de profissionalização para inserção no mercado de trabalho ou voltadas para ações que fomentem o aumento da renda familiar. Não atendido.

\section{RESULTADOS E CONSIDERAÇÕES FINAIS}

Após análise dos 53 critérios do Selo (Tabela 1), verificou-se que o projeto do Residencial Bairro Carioca não obteria nem a gradação Bronze do Selo Casa Azul, uma vez que atende somente parte dos critérios obrigatórios; apenas 11 dos 19 foram alcançados (58\%).

Apesar disso, foram atendidos 24 critérios, isto é, 45\% do total coforme Tabela 2 a seguir.

Quadro 1: Checklist; verde - atendido/vermelho - não atendido.

\begin{tabular}{|c|c|c|c|}
\hline \multicolumn{4}{|c|}{ CATEGORIAS/CRITÉRIOS } \\
\hline 1. QUALIDADE URBANA & & & \\
\hline 1.1 Qualidade do Entorno - Infraestrutura & obrigatório & 4.3 Componentes Industrializados ou Pré-fabricados & \\
\hline 1.2 Qualidade do Entorno - Impactos & obrigatório & 4.4 Formas e Escoras Reutilizáveis & obrigatório \\
\hline 1.3 Melhorias no Entorno & & 4.5 Gestão de Resíduos de Construção e Demolição (RCD) & obrigatório \\
\hline 1.4 Recuperação de Áreas Degradadas & & 4.6 Concreto com Dosagem Otimizada & \\
\hline 1.5 Reabilitação de Imóveis & & 4.7 Cimento de Alto-Forno (CPIII) e Pozolânico (CP IV) & \\
\hline 2. PROJETO E CONFORTO & & 4.8 Pavimentação com RCD & \\
\hline 2.1 Paisagismo & obrigatório & 4.9 Madeira Plantada ou Certificada & \\
\hline 2.2 Flexibilidade de Projeto & & 4.10 Facilidade de Manutenção da Fachada & \\
\hline 2.3 Relação com a Vizinhança & & 5. GESTÃO DA ÁGUA & \\
\hline 2.4 Solução Alternativa de Transporte & & 5.1 Medição Individualizada - Água & obrigatório \\
\hline 2.5 Local para Coleta Seletiva & obrigatório & 5.2 Dispositivos Economizadores - Sistema de Descarga & obrigatório \\
\hline 2.6 Equipamentos de Lazer, Sociais e Esportivos & obrigatório & 5.3 Dispositivos Economizadores - Arejadores & \\
\hline 2.7 Desempenho Térmico - Vedações & obrigatório & 5.4 Dispositivos Economizadores - Registro Regulador Vazão & \\
\hline 2.8 Desempenho Térmico - Orientação ao Sol e Ventos & obrigatório & 5.5 Aproveitamento de Águas Pluviais & \\
\hline 2.9 Iluminação Natural de Áreas Comuns & & 5.6 Retenção de Águas Pluviais & \\
\hline 2.10 Ventilação e Iluminação Natural de Banheiros & & 5.7 Infiltração de Águas Pluviais & \\
\hline 2.11 Adequação às Condições Físicas do Terreno & & 5.8 Áreas Permeáveis & obrigatório \\
\hline 3. EFICIÊNCIA ENERGÉTICA & & 6. PRÁTICAS SOCIAIS & \\
\hline 3.1 Lâmpadas de Baixo Consumo - Áreas Privativas & obrigatório & 6.1 Educação para a Gestão de RCD & obrigatório \\
\hline 3.2 Dispositivos Economizadores - Áreas Comuns & obrigatório & 6.2 Educação Ambiental dos Empregados & obrigatório \\
\hline 3.3 Sistema de Aquecimento Solar & & 6.3 Desenvolvimento Pessoal dos Empregados & \\
\hline 3.4 Sistemas de Aquecimento à Gás & & 6.4 Capacitação Profissional dos Empregados & \\
\hline 3.5 Medição Individualizada - Gás & obrigatório & 6.5 Inclusão de trabalhadores locais & \\
\hline 3.6 Elevadores Eficientes & & 6.6 Participação da Comunidade na Elaboração do Projeto & \\
\hline 3.7 Eletrodomésticos Eficientes & & 6.7 Orientação aos Moradores & obrigatório \\
\hline 3.8 Fontes Alternativas de Energia & & 6.8 Educação Ambiental dos Moradores & \\
\hline 4. CONSERVAÇÃO DE RECURSOS MATERIAIS & & 6.9 Capacitação para Gestão do Empreendimento & \\
\hline 4.1 Coordenação Modular & & 6.10 Ações para Mitigação de Riscos Sociais & \\
\hline 4.2 Qualidade de Materiais e Componentes & obrigatório & 6.11 Ações para a Geração de Emprego e Renda & \\
\hline
\end{tabular}

Quadro 2: Percentuais de Critérios Atendidos

\begin{tabular}{|c|c|c|c|c|c|c|c|}
\hline \multirow{2}{*}{ CATEGORIAS } & \multicolumn{2}{|c|}{ Existentes } & \multicolumn{2}{|c|}{ Atendidos } & \multicolumn{3}{|c|}{ Percentual } \\
\hline & $\mathrm{CO}$ & CF & $\mathrm{CO}$ & CF & $\mathrm{CO}$ & CF & Total \\
\hline 1. QUALIDADE URBANA & 2 & 3 & 1 & 3 & $50 \%$ & $100 \%$ & $80 \%$ \\
\hline 2. PROJETO E CONFORTO & 5 & 6 & 1 & 3 & $20 \%$ & $50 \%$ & $36 \%$ \\
\hline 3. EFICIÊNCIA ENERGÉTICA & 3 & 5 & 2 & 0 & $67 \%$ & $0 \%$ & $25 \%$ \\
\hline 4. CONSERVAÇÃO DE RECURSOS MATERIAIS & 3 & 7 & 3 & 5 & $100 \%$ & $71 \%$ & $80 \%$ \\
\hline 5. GESTÃO DA ÁGUA & 3 & 5 & 3 & 1 & $100 \%$ & $20 \%$ & $50 \%$ \\
\hline 6. PRÁTICAS SOCIAIS & 3 & 8 & 1 & 1 & $33 \%$ & $13 \%$ & $18 \%$ \\
\hline TOTAL PARCIAL & 19 & 34 & 11 & 13 & $58 \%$ & $38 \%$ & $45 \%$ \\
\hline TOTAL & \multicolumn{2}{|c|}{53} & \multicolumn{2}{|c|}{24} & \multicolumn{3}{|c|}{$45 \%$} \\
\hline \multicolumn{8}{|l|}{$\mathrm{CO}$ - critérios obrigatórios } \\
\hline CF - critérios facultativos & & & & & & & \\
\hline
\end{tabular}


Em relação as categoria, constata-se que a Qualidade Urbana teve $80 \%$ dos créditos atendidos, principalmente devido ao empreendimento estar totalmente inserido na malha urbana. A questão do ruído constante relatado pelos moradores dos prédios localizados junto à divisa nordeste do terreno, colada a linha férrea e a linha 2 do metrô, impediu a obtenção do crédito 1.2, obrigatório.

Quanto à categoria Projeto e Conforto, apenas 36\% dos critérios foram atendidos; a questão econômica influenciou decisivamente neste fraco desempenho, inviabilizando um projeto paisagístico que protegesse as fachadas dos blocos residenciais e estratégias para sombreamento das aberturas. Também, para atender a grande demanda de unidades habitacionais, não houve possibilidade de uma implantação dos blocos que obedecesse a um estudo de orientação solar e ventilação.

A Eficiência Energética teve um péssimo desempenho, com apenas $25 \%$ dos critérios atendidos; não só não houve fornecimento de lâmpadas de baixo consumo nas unidades (obrigatório para empreendimentos de HIS), como foram instaladas tomadas nos banheiros das unidades para posterior aquisição de chuveiro elétrico pelos moradores.

A categoria Conservação dos Recursos Materiais teve boa pontuação, cumprindo $80 \%$ dos critérios, em boa parte pela larga utilização de pré-fabricação, causando menos desperdício e reduzindo seu prazo de execução.

Em relação à Gestão da Água todos os critérios obrigatórios foram atendidos.

A categoria Práticas Sociais foi a menos atendida, tanto durante a obra quanto na pós-ocupação; alguns trabaIhos sociais foram desenvolvidos na época da entrega das unidades habitacionais, mas apenas para alguns lotes, não atingindo a totalidade dos moradores.

Para o empreendimento analisado, verificou-se que as facilidades de mobilidade e a proximidade de serviços públicos foram fundamentais para alcançar alguns critérios, mas o projeto arquitetônico dos prédios habitacionais deixou a desejar. Mesmo sem ter tido acesso às planilhas de custo do empreendimento, fica evidente que o baixo valor da unidade habitacional imposto para a faixa 1 do PMCMV, é o fator que mais dificulta o cumprimento de alguns critérios. Também a busca pela maior quantidade possível de unidades habitacionais, outra característica dos empreendimentos deste Programa, não permite uma implantação dos blocos segundo melhor orientação solar e ventilação predominante, o que sem dúvida beneficiaria a questão da eficiência energética e do conforto ambiental.

Pela análise dos resultados obtidos com a aplicação do checklist do Selo Casa Azul, fica claro seu potencial para ser utilizado como ferramenta na busca de uma edificação mais sustentável, já que os itens obrigatórios não atendidos são fundamentais neste sentido. Infelizmente a adesão ao selo não é obrigatória para projetos do PMCMV, em especial os da faixa 1, como é o caso do Bairro Carioca, destinados à população de renda mais baixa, justamente a que mais necessita de uma habitação que possibilite custos mais baixos de operação e manutenção.

\section{REFERÊNCIAS}

ASSOCIAÇÃO BRASILEIRA DE NORMAS TÉCNICAS. NBR 15220: Desempenho Térmico de edificações. Rio de Janeiro, 2003.

BRASIL. Ministério das Cidades. Disponível em <http:// www.cidades.gov.br/ultimas-oticias/3865-ministro-das-cidades-apresenta-fase-3-do-mcmv-a-deputados-da-comissao-de-desenvolvimento-urbano>, acesso em 24/08/2016.

CAIXA. Mudanças Selo Casa Azul. Disponível em <http://www.caixa.gov.br/Downloads/selo_casa_azul/ Mudancas_Selo_Casa_Azul.pdf>, acesso em maio/2016.

CAIXA. Selo Casa Azul - Boas Práticas para Habitação mais Sustentável; Coordenadores Vanderley Moacyr John, Racine Tadeu Araújo Prado. São Paulo: Páginas \& Letras. Editora e Gráfica, 2010 disponível em <http://www.caixa.gov.br/site/paginas/downloads.aspx>, acesso em abril/2016.

CARDOSO, A. L. (Org). O Programa Minha Casa Minha Vida e seus Efeitos Territoriais. Rio de Janeiro: Letra Capital Editora, 2013.

GEOGRAFOS; Coordenadas Geográficas; disponível em < http://www.geografos.com.br/cidades-rio-de-janeiro/rio-de-janeiro.php>, acesso em setembro/2016.

IDHEA - Instituto para o Desenvolvimento da Habitação Ecológica; disponível em <http://www.idhea.com.br/ construcao_sustentavel.asp>, acesso em 23/03/2016.

INMET - Instituto Nacional de Meteorologia; disponível em <http://www.inmet.gov.br/portal/index.php?r=estacoes/estacoesAutomaticas $>$, acesso em abril/2016.

LABEEE Laboratório de Eficiência Energética em Edificações. Software SOL-AR 6.2. Disponível para 
download em <http://www.labeee.ufsc.br/> , acesso em setembro/2016.

LAMBERTS, R.; PEREIRA, F.; DUTRE, L.; GOULART, S. - Eficiência Energética na Arquitetura (CD e livro). Editores, 1998.

MAGALHÃES, Sérgio. Modelo não inclui morador como protagonista. Folha de São Paulo, 19 fev. 2011.

MCTARNAGHAN, S.; Bairro Carioca é modelo de conjunto habitacional; disponível em <http://www. brasil247.com/pt/247/favela247/156434/Bairro-Carioca\%C3\%A9-modelo-de-conjunto-habitacional.htm>, outubro de 2014. Acesso em 07/12/2016.

PREFEITURA DA CIDADE DO RIO DE JANEIRO. Bairro Carioca - Habitação Social para um novo Rio: Publicação produzida em conjunto por Direcional Engenharia S/A e STA Arquitetura S/A. Gráfica Santa Marta. 2011.

ROLNIK, R.. Guerra dos lugares - A colonização da terra e da moradia na era das finanças. Editora Boitempo - São Paulo, SP, 2015. 